\title{
OBRAS SOCIALES PROVINCIALES: INDICADORES DE CONSUMO Y GASTO EN ATENCIÓN MÉDICA
}

\author{
Sandra Canale (*) \\ Héctor De Ponti $(\cdot \cdot)$ \\ Mariano Monteferrario ( $\cdots$ ) \\ Universidad Nacional del Litoral
}

\section{RESUMEN}

El sistema de salud argentino se caracteriza por su heterogeneidad y fragmentación, lo que genera inconvenientes en la eficiencia asignativa. Según datos del último censo, la sumatoria de la población cubierta por las jurisdicciones provinciales a través de la salud pública y de la que posee cobertura de la seguridad social provincial, representa - en promedio- el $52 \%$ de la población del país, cifra que evidencia el rol fundamental que ocupan los estados provinciales en la construcción de políticas públicas sanitarias y la necesaria interacción que requiere el sector, para poder generar una sinergia positiva de las partes. En este artículo, se expone información relevada a través del Observatorio de la Seguridad Social Provincial que permite identificar el grado de cobertura del Sistema de Salud Argentino para los distintos segmentos y analizar la estructura demográfica cubierta por las Obras Sociales Provinciales, en pos de aportar datos para caracterizar demográficamente la población bajo cobertura y exponer indicadores de consumo y costo.

\section{PALABRAS CLAVE:}

\section{KEY WORDS:}

obras sociales, atención medica, indicadores de consumo/gasto.

healthcare, medical assistance, consumption/expense indicators.

(•)E-mail: sandracanale1@gmail.com

RECEPCIÓN: 15/10/15

(••)E-mail: hdeponti@hotmail.com

ACEPTACIÓN FINAL: 12/05/16 